CHAPTER 21

\title{
Geochemistry of the Central and Western Structures
}

\author{
Charlotte Rowley, Charles French and Nicky Milner
}

\section{Introduction}

Multi-element soils analysis is a well-established avenue of research within archaeological projects (e.g. Entwistle and Abrahams 1997; Wilson et al. 2008; Linderholm 2010; Dore and López Varela 2010). However, comprehensive horizontal surveys of sites have most often been applied to sites with clear structures or limits; either natural (such as cave floors, as in Homsey and Capo 2006) or anthropogenic (such as buildings, e.g. Middleton and Price 1996; Vyncke et al. 2011). These confine the potential zones of activity and also often provide a degree of protection by sheltering the sediments.

In contrast, perhaps because Mesolithic sites do not tend to have clear structures, there has been very little multi-elemental analysis carried out on sites of this period. Where it is undertaken, it is sometimes carried out vertically through the sediments as opposed to looking for horizontal spatial patterning (Mikołajczyk and Schofield 2016). However, where remnants of buried soils are present, either in situ or redeposited in shallow features, there is the possibility that ephemeral geochemical signatures of past activities could be identified (Wilson et al. 2008).

The research undertaken at Star Carr aimed to explore the potential of multi-element soil geochemistry in Mesolithic contexts, as well as to see what information the results could provide about spatial activities across the site. Two areas with potential were sampled: the central and western dryland structures. Micromorphology was also undertaken within the central structure. Soil samples from both areas were analysed using inductively coupled plasma atomic emission spectroscopy (ICP-AES) in the laboratory. Patterning of seven key individual elements are analysed here. Grouping Analysis, a cluster analysis method deploying a k-means++ algorithm, was conducted on ArcGIS 10.4.1 and Principal Component Analysis was conducted on SPSS 24 and OriginPro 2016.

\section{How to cite this book chapter:}

Rowley, C., French, C. and Milner, N. 2018. Geochemistry of the Central and Western Structures. In: Milner, N., Conneller, C. and Taylor, B. (eds.) Star Carr Volume 2: Studies in Technology, Subsistence and Environment, pp. 161-173. York: White Rose University Press. DOI: https://doi.org/10.22599/book2.g. Licence: CC BY-NC 4.0 


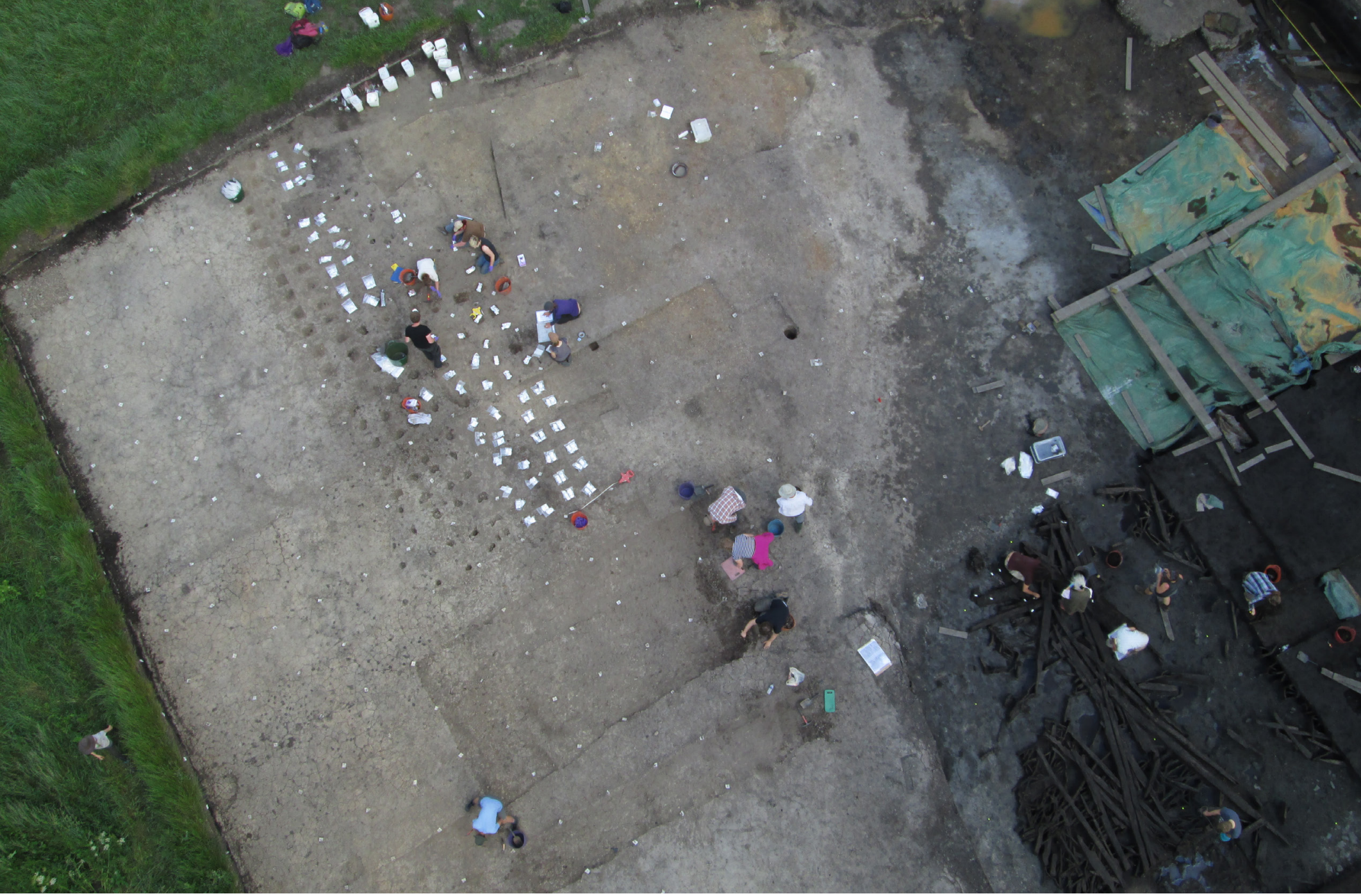

Figure 21.1: Sampling over the central structure: the eastern trench edge is at the top of the photo and the western platform can be seen in the bottom right corner (kite photograph taken by Sue Storey) (Copyright Sue Storey, CC BY-NC 4.0).

\section{Methods}

\section{Sampling}

The sampling took place in 2014 when excavating the central structure and surrounding occupation spread and in 2015 when excavating the western structure. The central area was chosen because it revealed postholes and an adjacent, delimited spread of sediment which was significantly different to the surrounding deposits (termed 'occupation spread') and which is thought to have been a very thin buried soil (Chapter 20). Two sets of samples were taken from both the top of the central structure and from lower down in the context, towards the base. The uppermost sample results are considered in this study. In addition, sample blocks for micromorphology were taken from the central structure. For most of the rest of the dryland, the transition between degraded peat and underlying clayey deposits was not clearly defined (Chapter 20). In total, 189 samples were selected from around the central structure occupation spread, including seven control samples taken from the underlying clay (308: remnants of the B horizon grading into till; from here referred to as till).

The area around the western structure was much less clear and this was only sampled because it appeared to have darker smears within it, possible postholes and large quantities of flint (Chapters 5 and 8). Twenty-four samples were taken from this area at the level where the potential postholes had been noticed, at about $0.1 \mathrm{~m}$ below the interface between contexts (302: grey/brown clay) and (308) (Chapter 20).

The method of sampling had been trialled at the site of Flixton Island 2 in 2012 (Rowley in prep). A total of 505 samples were taken from Star Carr in spits on a $0.5 \mathrm{~m} \times 0.5 \mathrm{~m}$ grid (aligned with the $1 \mathrm{~m}$ site grid). 


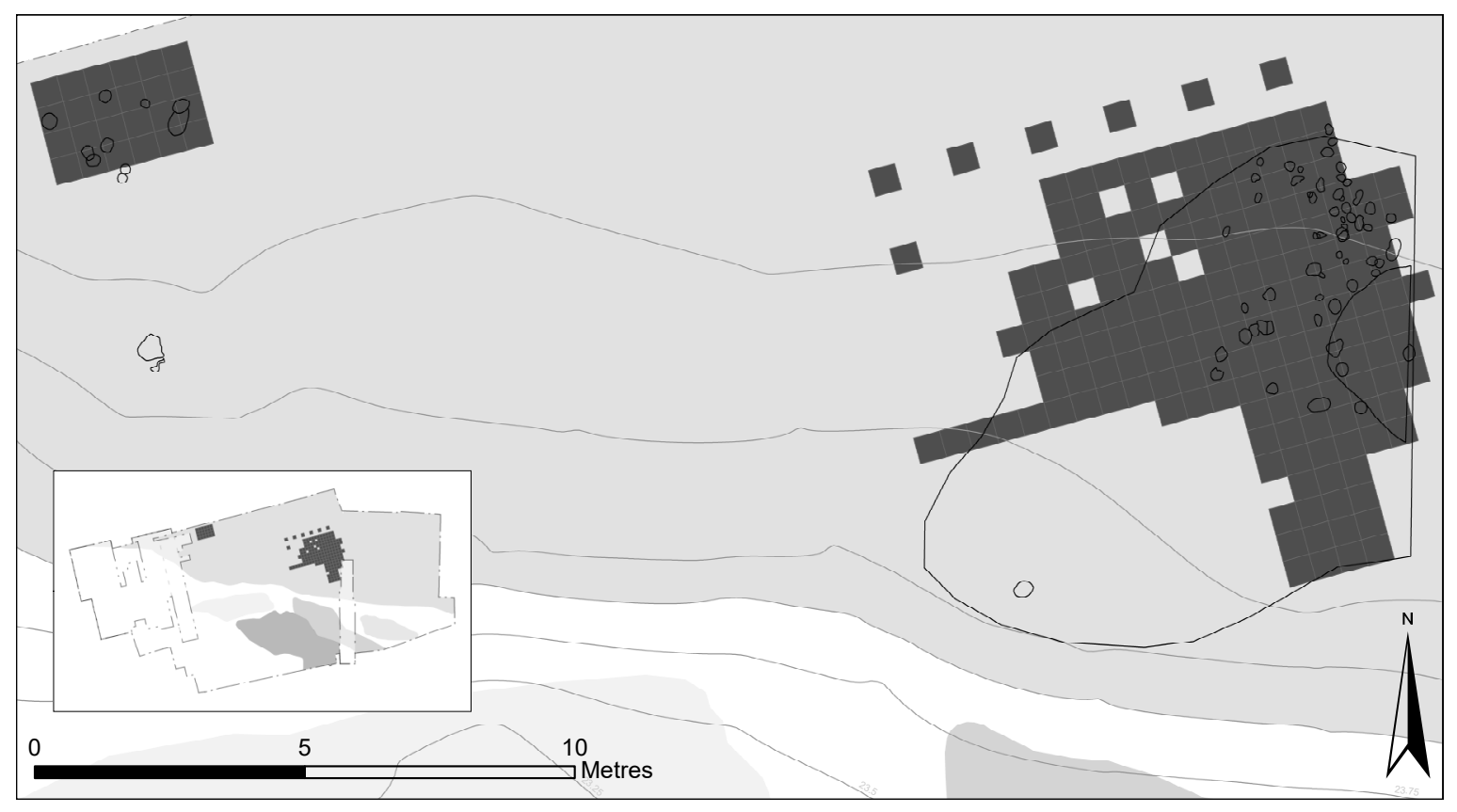

Figure 21.2: The grid of soil samples examined using ICP-AES, shaded in dark grey. Most of the samples cover the occupation spread (Chapter 20) and structures contiguously, but seven separate squares were also sampled from the till to the north of the central structure area (Copyright Charlotte Rowley, CC BY-NC 4.0).

Samples were taken using trowels (cleaned between each sample) with the sampling team wearing a fresh set of non-powdered nitrile gloves per sample. Samples of around $100 \mathrm{~g}$ were taken from a cleaned back, freshly excavated surface. The soil was placed into aluminium foil packets to exclude light and then placed individually into labelled resealable bags. In the lab, a pilot study of 29 samples was first submitted for ICP-AES to test whether there would be any differentiation in the results. The results suggested potential for spatial differentiation in the elemental composition of the sediment and so a larger sample was selected.

\section{ICP-AES analysis}

Multi-element analyses using ICP-AES (Wilson et al. 2008) were carried out by ALS Global using the aqua regia digestion method (ALS Minerals 2009). ICP-AES was conducted on dried, sorted fine fractions by ALS Global (procedure code: ME-ICP41). Samples were decomposed in aqua regia in a graphite heating block. The resulting solution was diluted to $12.5 \mathrm{ml}$ with deionised water and then analysed. ALS Minerals Loughrea, a subdivision of ALS Global, conducted the analyses on either a Varian 725 RD ICP-OES system or an Agilent Technologies ICP-OES system (Louise Clarke, ALS Global, pers. comm. 2016). The spectrometers used a method template containing 61 analytical lines and 28 interferent lines. The detection limits of this method for the seven elements discussed in this chapter are summarised in Table 21.1. The results are corrected for inter-elemental spectral inferences by ALS Global.

A total of 35 elements were analysed. From the results, six elements were selected for this statistical study as they made the highest contributions to the composition of the samples: aluminium ( $\mathrm{Al})$, calcium (Ca), iron $(\mathrm{Fe})$, potassium $(\mathrm{K})$, magnesium $(\mathrm{Mg})$ and phosphorus $(\mathrm{P})$. Manganese $(\mathrm{Mn})$ was also included because it showed a high degree of variability across site (from $17 \mathrm{ppm}$ up to $700 \mathrm{ppm}$ ). These are all standard elements considered in other soil analysis applications. Other elements available, such as sulfur, were minor or trace contributors to these specific samples and will be considered in future work.

It should be noted that aluminium, iron and manganese are all naturally occurring precipitates in the soils on the site, and particularly in subsoils on top of the clayey till substrate, from the gradual weathering and 


\begin{tabular}{|l|l|l|r|r|}
\hline Element & Symbol & Units measured in & Lower limit (same units) & Upper limit (same units) \\
\hline Aluminium & $\mathrm{Al}$ & $\%$ & 0.01 & 25 \\
\hline Calcium & $\mathrm{Ca}$ & $\%$ & 0.01 & 25 \\
\hline Iron & $\mathrm{Fe}$ & $\%$ & 0.01 & 50 \\
\hline Potassium & $\mathrm{K}$ & $\%$ & 0.01 & 10 \\
\hline Magnesium & $\mathrm{Mg}$ & $\%$ & 0.01 & 25 \\
\hline Manganese & $\mathrm{Mn}$ & $\mathrm{ppm}$ & 5 & 50000 \\
\hline Phosphorus & $\mathrm{P}$ & $\mathrm{ppm}$ & 10 & 10000 \\
\hline
\end{tabular}

Table 21.1: Detection limits for key elements discussed in this chapter when analysed through ICP-AES, as conducted by ALS Global.

solifluction due to the erratic water levels in the general area. As the structures are on the dryland area of the site, they are better drained but they will still have been saturated from time to time and subject to groundwater level fluctuations post-occupation. As such, iron, manganese, aluminium and possibly calcium enrichment may be related to groundwater fluctuations, being potentially derived from the substrate below the site.

\section{Grouping Analysis}

The results of the analyses were integrated as attributes of a polygon representing the sampling grid on ArcGIS. Plots of the individual elements' spatial distributions were symbolised using the Jenks natural breaks option, which divides data into classes based on natural groups in the data itself (in this case into five groups). Grouping Analysis, available in the Spatial Statistics toolbox, was selected as one of the methods to further explore the output dataset from the ICP-AES analyses. The output results from this tool are in the form of a visual plot of grouped samples based on multiple attributes as well as a breakdown of the groupings' traits. This provides an easy-to-understand means of exploring and visually examining the data. Like other algorithms for cluster and component analysis, it is a way of looking for trends in more complex datasets with higher numbers of variables that may correlate positively or negatively. However, the solution of a model from any cluster analysis algorithm is classed as computationally difficult ('NP-hard'), so it is not possible to ensure the optimal solution has been found from one run or one tool. As such, results must be compared and interpreted judiciously but can inform about the underlying structures in the dataset (ESRI nd).

The ArcGIS Grouping Analysis tool clusters features based on trends in their attributes and symbolises features accordingly to produce a visual plot. In this case, sample squares were grouped by their elemental composition traits measured in parts per million. The values are automatically standardized by the tool, using a $\mathrm{z}$-transform, to reduce over-influence of variables with naturally large variances. Groupings were purely based on elemental composition, not the spatial proximity of samples to each other. The groupings were not spatially constrained, i.e. samples did not need to be contiguous to be grouped. A k-means++ algorithm is utilised for calculating the clusters with this setup (Arthur and Vassilvitskii 2007).

One potential issue might be that the samples might be grouped because they are close together and are therefore naturally similar. In order to test this, repeat runs were conducted first on the data from the contiguous samples from both structures, but not the till. Similarly, further repeat runs were conducted on the contiguous samples from just the central occupation area. The group patterning, seen in the analyses for the complete sample, were maintained across the repeat runs and therefore the general variance in different areas does not appear to have been influential in the formation of the groups.

The tool has to be told where to grow the analysis of groups from, called 'seed features'. Once seeds are identified, all data points are assigned to the most similar seed feature. A mean data centre is then computed for each group and the points are repeatedly assigned to the closest centre until the model is stable. The number of seeds that are used to grow the groups is the same as the number of groups being defined (e.g. specifying for six groups means six seeds will be employed). These seeds can be prespecified, completely randomised or selected by the tool to optimise group differentiation after random initialisation. Here the latter (optimised) 
method was selected. As such, there can still be slight variations in results from repeated runs of the tool due to the randomness in initialisation.

The Grouping Analysis tool can statistically suggest the optimal number of groups, based on the highest pseudo F-statistics. The results of this varied due to the randomised seed initialisation of each run. The optimal number of groups established by repeat runs of the algorithm on the upper dataset suggested between six and 10 but more likely at the higher end of that range (nine or 10). Four repeat runs of the tool when set to identify nine statistical groups in the upper dataset identified several reasonably consistent groupings. For the lower dataset, the suggested optimal numbers were between seven and 12, but eight was most commonly generated and again produced reasonably consistent groupings. These ranges suggest that the patterning of the elements in the samples is complex but the consistency of groupings both between repeat runs on the same dataset and when comparing the upper and lower datasets of the central structure supports the identification of robust groupings. This is unsurprising given the interplay of many natural processes affecting the soils at Star Carr, as well as any potentially compounding influences from anthropogenic processes.

\section{Principal Component Analysis}

The ICP-AES results were also loaded into SPSS 24 and OriginPro 2016 as datasheets in order to run Principal Component Analysis (PCA). K-means clustering, as employed for the grouping analysis, aims to group the samples themselves. PCA, on the other hand, aims to reduce the dimensions in the data by grouping variables into linear, uncorrelated variates (linear combinations called components) that capture as much of the variance as possible (Ding and He 2004; Field 2009). As such, if the scores on components identified using PCA group together and are consistent with the groupings identified from the k-means++ clustering then it would suggest support for the groupings based on the geochemistry.

Principal Component Analysis (PCA) was conducted in OriginPro 2016 and with no rotation applied in SPSS. The Kaiser-Meyer-Olkin measure verified the sampling adequacy for the analysis $(\mathrm{KMO}=0.702$, rating 'good' and all KMO values for individual variables were $>0.5$, the acceptable limit, according to Field 2009). Bartlett's test of sphericity $\chi^{2}(10)=437.189, \mathrm{p}<0.001$, indicated that correlations between items were sufficiently large for PCA. Preliminary evaluation of intercorrelation between variables led to the exclusion of certain elements available in the ICP-AES dataset to improve robustness of the model. As such, five of the seven elements were incorporated into the established robust final statistical model: aluminium (Al), calcium $(\mathrm{Ca})$, iron $(\mathrm{Fe})$, magnesium $(\mathrm{Mg})$ and manganese $(\mathrm{Mn})$. Phosphorus and potassium had to be excluded on the grounds they generally did not correlate well with any of the other five elements or each other and therefore could not be included confidently in the linear components identified.

One component had an eigenvalue over Kaiser's criterion of 1 which would explain just 58.96\% of the variance in the global dataset if extracted on its own. By Joliffe's criterion of 0.7, we could extract three variables. The scree plot showed a point of inflexion that would justify retaining three components, although values still dropped off further after the inflexion. All communality values were above the recommended threshold of 0.7 after extraction, which indicates that the amount of variance in each variable is adequately explained by the retained factors. Given the small (yet theoretically adequate) sample size, the communality values generated, the convergence of the scree plot and Joliffe's criterion on three components, the number of components on the final analysis was taken as three. This explained $91.95 \%$ of the variance in the samples.

\section{Results}

\section{Micromorphology}

The micromorphology sample blocks from the central structure (sample 2007, tins 1 to 3 ) and particularly the tin highest up in the stratigraphy, contained moderate to minor amounts of degraded bone (c. $10 \%$ in the upper tin, as shown in Figure 21.3(a)), charred organics $(<50 \mu \mathrm{m})$, ash $(<2 \%$, Figure 21.3(b)) as well as amorphous sesquioxide and phosphate replaced plant tissue (c. 10\%, Figure 21.3(c)) and groundmass 'cemented' with amorphous sesquioxides. In summary, this suggests that while the sediments contained anthropogenic debris that had possibly been within the structure, they were disturbed and mixed and the bone had evidently been affected by the acidity and groundwater fluctuations. 


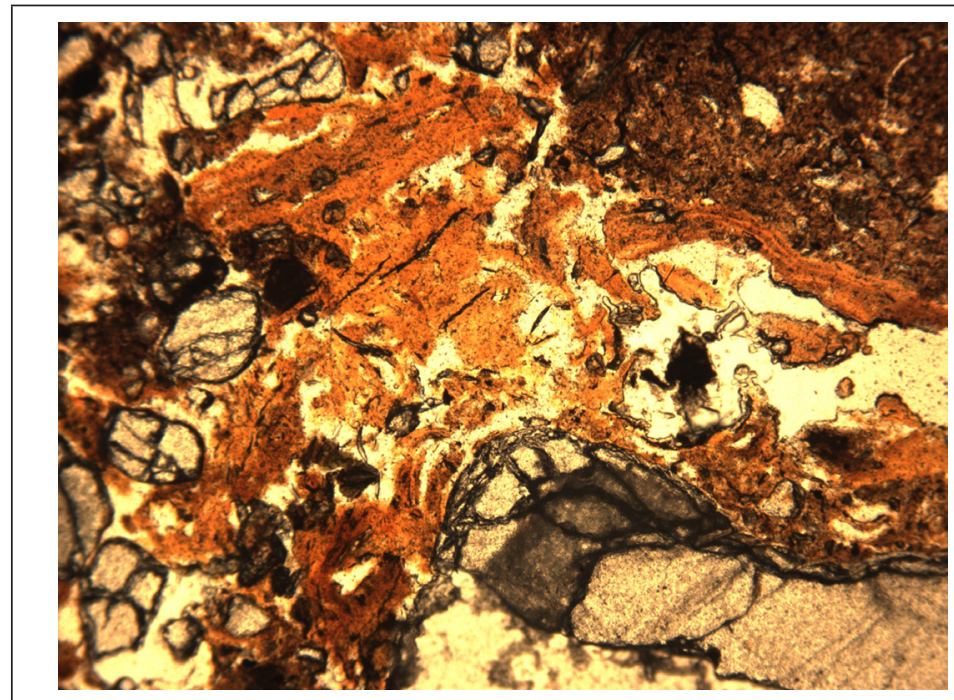

a) Phosphatised, partially degraded

bone in sample 2007, tin $1(4.5 \mathrm{~mm}$

frame width; plane polarized light)

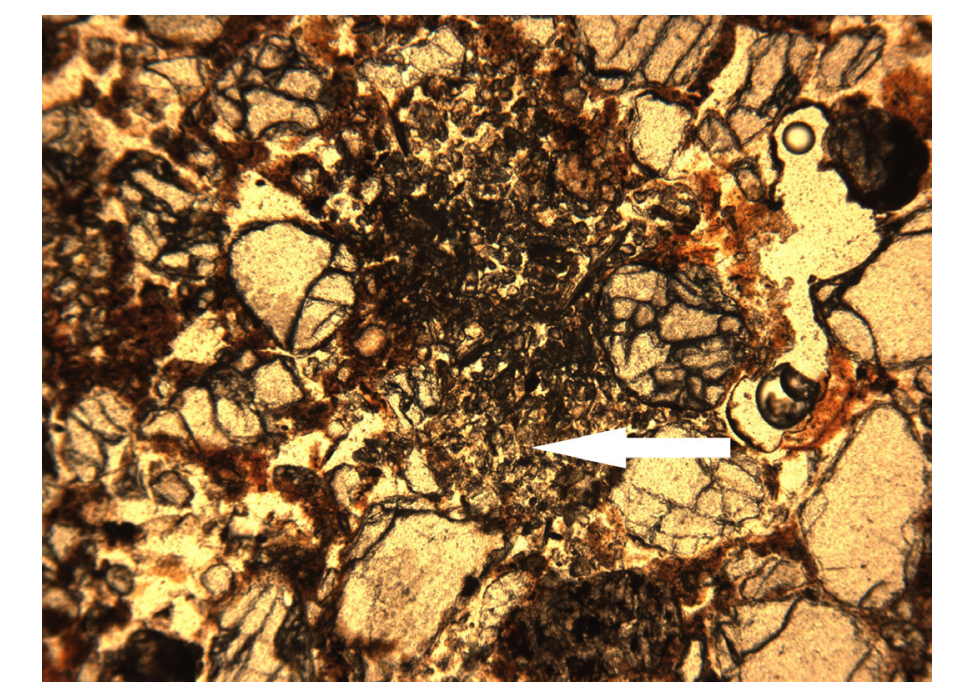

b) Ash in the groundmass of sample 2007, tin 1 (4.5 mm frame width; plane polarized light)

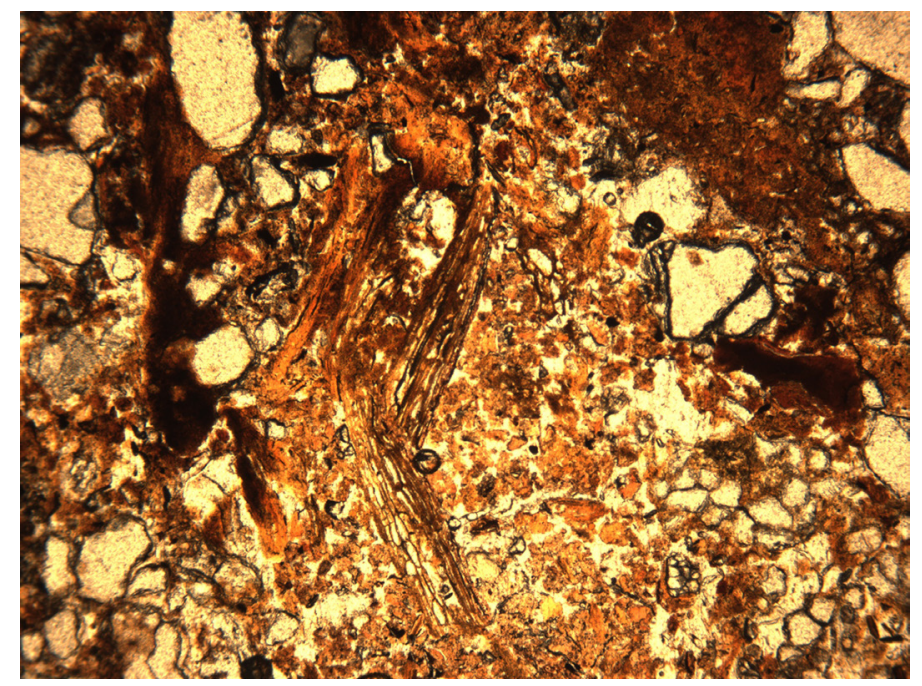

c) Sesquioxide and phosphate replaced plant tissues and bone in sample 2007, tin 1 (4.5 $\mathrm{mm}$ frame width; plane polarized light)

Figure 21.3: Relevant features identified from the micromorphological analysis on the blocks from the central structure (Copyright Charles French, CC BY-NC 4.0). 


\section{Assessing the background values}

Assessing the background values of elements is not straightforward because glacial till is inherently highly variable in material composition, being largely composed of redeposited material from across potentially very long distances; therefore we would expect this to be reflected to some extent in the samples from site. However, to give a sense of the general geochemical composition of the till, the descriptive statistics from the till samples more than $1 \mathrm{~m}$ from the recorded occupation spread contexts are provided in Table 21.2.

In comparison, Boston (2007) conducted a geochemical examination by ICP mass spectrometry of a sample of glacigenic sediments from eastern England, the closest sites being from Skipsea and Filey (Table 21.3). As expected, she found the till composition reflected complex deposition dynamics and a high degree of variation. Despite this, for many elements a general similarity of concentrations for certain elements in parts per million (ppm) could be seen to differentiate the different till samples from different sites. Interestingly, however, Boston found that different tills from the same site could not be geochemically differentiated even when visually distinct (Clare Boston, pers. comm. 2016). Overall, Boston's work illustrates the variance in samples seen from tills across the east of the UK which can be compared with the geochemical readings from Star Carr.

\begin{tabular}{|l|r|r|r|r|r|r|r|}
\hline Value (ppm) & Al & Ca & Fe & K & Mg & Mn & P \\
\hline Minimum & 3500 & 1300 & 7100 & 200 & 700 & 17 & 90 \\
\hline Maximum & 31200 & 20000 & 46500 & 1700 & 6100 & 703 & 4750 \\
\hline Range & 27700 & 18700 & 39400 & 1500 & 5400 & 686 & 4660 \\
\hline Mean & 11320 & 3990 & 18907 & 646 & 3180 & 125 & 735 \\
\hline Median & 11500 & 3600 & 18000 & 500 & 3300 & 94 & 580 \\
\hline Mode & 11100 & 3500 & 17500 & 500 & 3500 & 88 & 550 \\
\hline Std. deviation (popul.) & 3978 & 1892 & 5665 & 363 & 965 & 98 & 622 \\
\hline
\end{tabular}

Table 21.2: Descriptive statistics for the major and key minor elements measured from samples recorded as till at Star Carr (values in parts per million).

\begin{tabular}{|l|l|r|r|r|r|r|r|r|}
\hline Value $(\mathrm{ppm})$ & & $\mathrm{Al}$ & $\mathrm{Ca}$ & $\mathrm{F}$ & $\mathrm{K}$ & $\mathrm{Mg}$ & $\mathrm{Mn}$ & $\mathrm{P}$ \\
\hline \multirow{2}{*}{ Skipsea tills } & Minimum & 4610.5 & 4322.5 & 6384.2 & 5689 & 517.3 & 113.9 & 1680.8 \\
\cline { 2 - 9 } & Maximum & 67988.2 & 134020.4 & 38636.1 & 21227.7 & 10612.2 & 965.9 & 12507.2 \\
\hline \multirow{2}{*}{ Filey tills } & Minimum & 17256.8 & 5930.3 & 19372.4 & 9438.7 & 629.3 & 301.1 & 11.7 \\
\cline { 2 - 9 } & Maximum & 42021.9 & 88532.7 & 43319.2 & 23397.3 & 11534.6 & 569.6 & 1321.1 \\
\hline
\end{tabular}

Table 21.3: Boston's readings in parts per million for tills at Skipsea and Filey, on the east coast, Yorkshire, from ICP-MS analysis (extracted from Boston 2007). 
Individual elemental results for the central occupation area

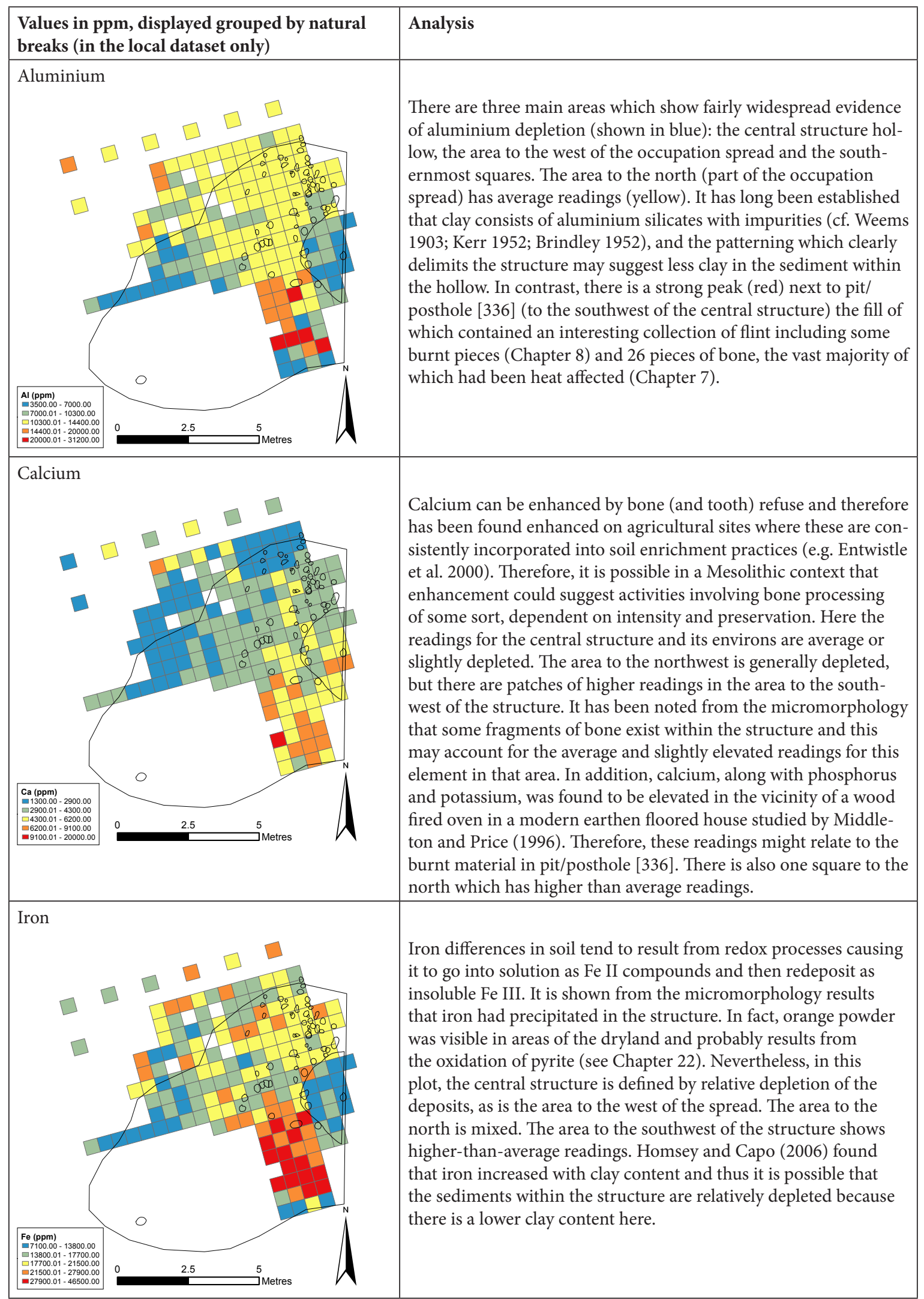




\begin{tabular}{|c|c|}
\hline $\begin{array}{l}\text { Values in ppm, displayed grouped by natural } \\
\text { breaks (in the local dataset only) }\end{array}$ & Analysis \\
\hline 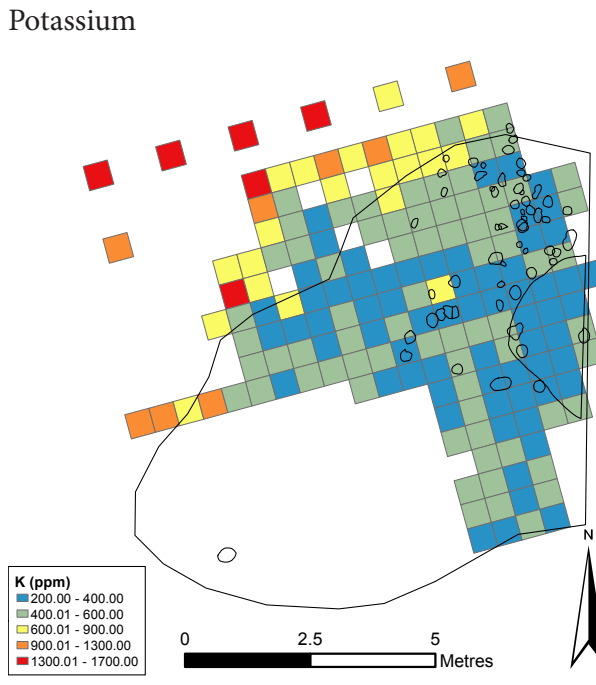 & $\begin{array}{l}\text { The presence of potassium can generally be enhanced by activi- } \\
\text { ties involving plants and has been associated with occupation } \\
\text { areas (Middleton and Price 1996; Entwistle et al. 2007). This } \\
\text { could be from deposition of residual wood ash as seen sometimes, } \\
\text { but inconsistently, in modern wood-burning contexts (Scotter } \\
\text { 1963). Potassium salts are highly soluble so would likely disap- } \\
\text { pear through leaching within a short period after the fires that } \\
\text { deposited them, but they could potentially fix in the clay content } \\
\text { of the soil and till (Stanford 1947; Oonk et al. 2009). In this case, } \\
\text { most of the occupation area, particularly the central structure, are } \\
\text { relatively depleted; whereas the till and the edge of the occupation } \\
\text { area appears to be relatively enhanced. This is either related to the } \\
\text { nature of the soils (the enhanced area is generally more clayey and } \\
\text { the occupation spread is more of a sandy/clayey loam) or there is } \\
\text { some depletion due to the nature of the occupation. }\end{array}$ \\
\hline 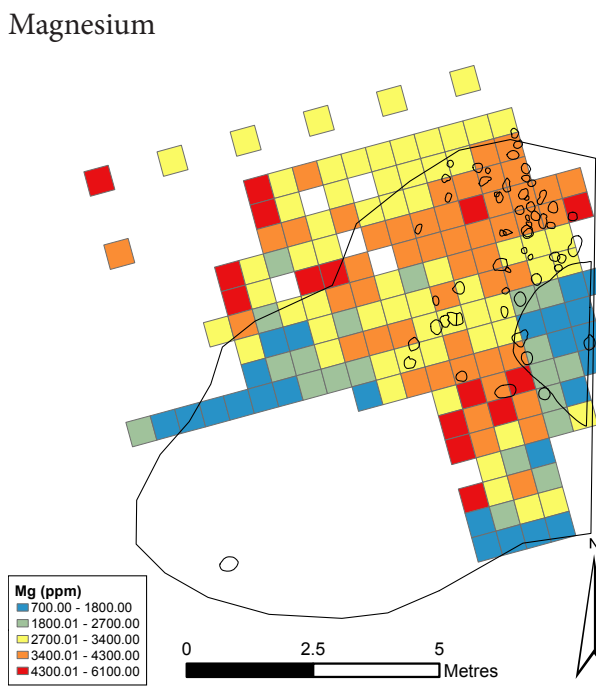 & $\begin{array}{l}\text { Magnesium can correlate with potassium, and is also generally } \\
\text { thought be associated with plant nutrients, wood ash, and wood } \\
\text { burning (see Scotter's } 1963 \text { work on forest fires; Middleton and } \\
\text { Price 1996; Oonk et al. 2009). Again, the salts are soluble but might } \\
\text { fix in the clays given suitable conditions (Oonk et al. 2009). The } \\
\text { patterning for this element shows depletion within the central } \\
\text { structure and some to the area to the west, as well as to the south } \\
\text { of the structure. High readings to the southwest of the structure } \\
\text { surround pit/posthole [336] containing burnt material. The pattern } \\
\text { is dissimilar to potassium in that the rest of the occupation spread } \\
\text { shows average and higher than average readings. Although ash was } \\
\text { found within the micromorphology samples from the structure, its } \\
\text { presence was so small and relatively infrequent that it was unlikely } \\
\text { to increase the elements noticeably, explaining the discrepancy } \\
\text { with these results. }\end{array}$ \\
\hline Manganese & $\begin{array}{l}\text { Manganese tends to be associated with iron as both are frequently } \\
\text { found in redox-induced deposits (Lindbo et al. 2010). This mineral } \\
\text { is mainly depleted across the area except for the central part of } \\
\text { the occupation spread which has no obvious relationship to any } \\
\text { archaeological features or any patterns from other elements. This } \\
\text { would suggest this is a natural phenomenon, and indeed manga- } \\
\text { nese oxide is found to occur in delimited areas across the site. }\end{array}$ \\
\hline 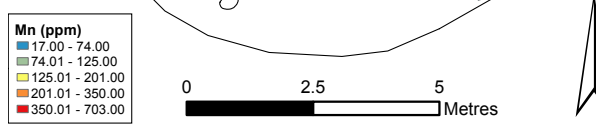 & \\
\hline
\end{tabular}

Figure 21.4: Continued 


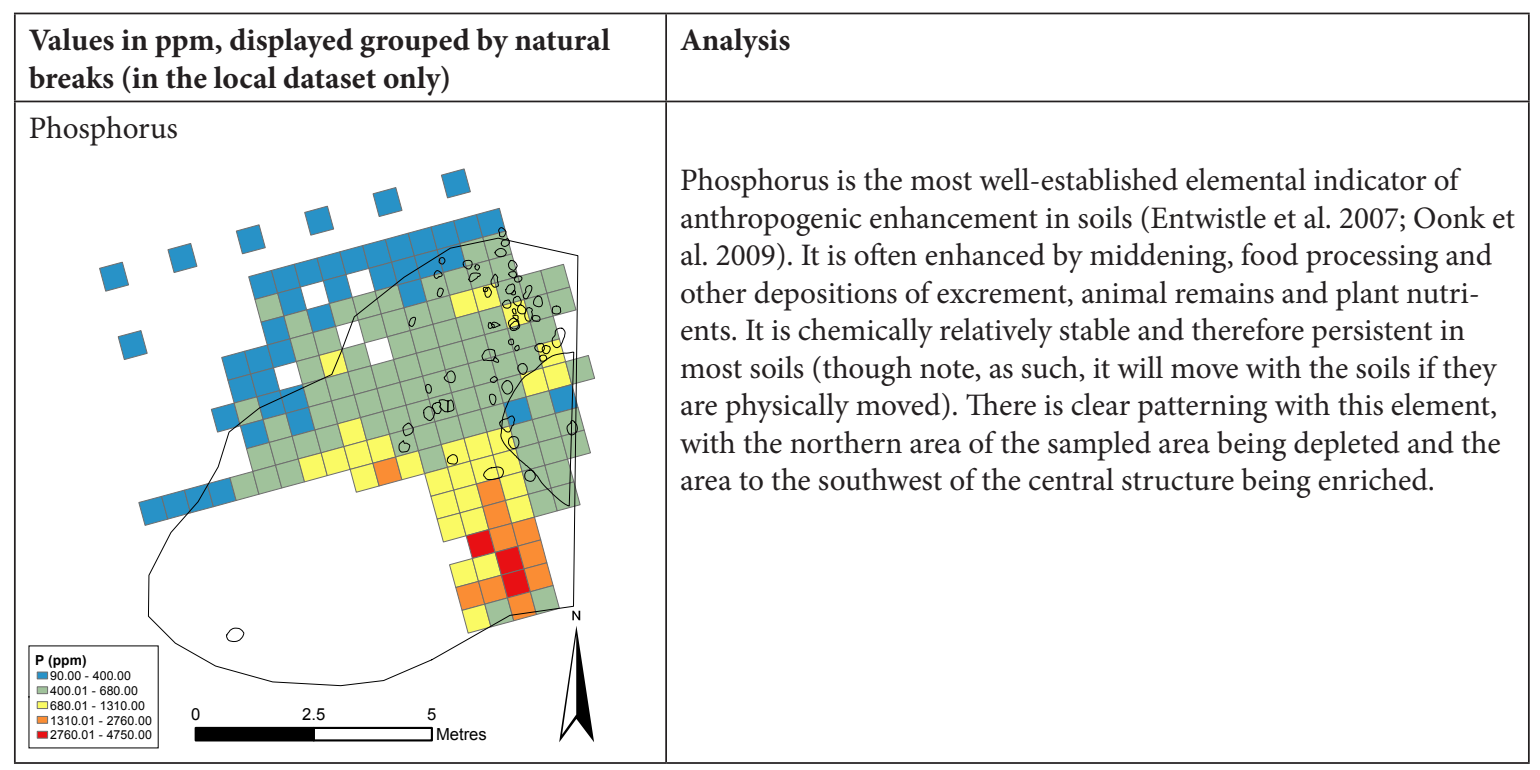

Figure 21.4: Plots of the central structure readings for each of the key elements, displayed by Jenks natural breaks in the non-normalized readings (in parts per million) (Copyright Charlotte Rowley, CC BY-NC 4.0).

The elements are analysed individually in Figure 21.4. The symbology displays the elements relative to the complete dataset from around the central structure. In summary, the central structure is defined in some of the plots, notably by aluminium, magnesium, iron and, to some degree, manganese. All of these can be affected by groundwater and depletion in these elements may be related to differential drainage in this feature. Middleton and Price (1996) found that aluminium, iron and magnesium all correlated well in an ethnographic study of a modern earthen floored residence and its surroundings. They argued the correlation was best explained by natural geochemical processes as the former two often co-occur as sesquioxides. When considering how pairs of elements correlate, aluminium and iron, and aluminium and magnesium, had the only two Pearson correlations above 0.7 from the Star Carr dataset, at 0.794 and 0.738 respectively, on a scale where zero is no correlation and one is $100 \%$ correlation. However, this cannot solely account for the depletion of these elements distinguishing the central structure.

In addition, phosphorus is often an indicator of human activity and whilst it is relatively elevated to the southwest of the structure, it is average/depleted in the squares of the structure. This perhaps suggests that the interior was kept relatively clean of waste from activities or at least treated differentially, with the area to the southwest of the structure being where refuse may have been deposited, either deliberately or accidentally, or otherwise influenced by the use of pit/posthole [336].

\section{Grouping Analysis results for the central and western occupation areas}

In order to examine these potential patterns further, Grouping Analysis was undertaken. Again, the results suggest some possible areas of interest. The first is the central structure, which has also been grouped with the western area of the central occupation spread (group 5 on Figure 21.5). These areas tend to be relatively depleted in most of the elements. In terms of the structure, we know that this area had been hollowed out and would have gradually filled up with sediment being brought in, perhaps on feet and maybe plants used as flooring. Importantly, this sediment would be different to the surrounding sediment and this may be why some elements are shown to be relatively depleted. For instance, clay often contains relatively high levels of aluminium and if the sediment that accumulated within the hollow was sandier than the surrounding area, this would have the apparent effect of 'diluting' aluminium content in this specific context. The western edge of the central area (also defined as group 5 in purple), does not relate to any features; however, there is the possibility that another 
structure had been built in this location but is no longer visible archaeologically, in terms of having clearly defined postholes or a hollow.

Group 2, coloured red in Figure 21.5, is dominant across a large proportion of the area. This is from the occupation spread area (Chapter 20). Within this are two distinct patches of group 3 (green). The northern spread of group 3 appears to be bounded by a semi-circle of postholes. These areas are not particularly clear when examining the individual elements except perhaps for manganese, and if this is a natural occurrence of this element it may be skewing the grouping analysis to some degree. However, it is clear that the grouping analysis distinguishes between the till (group 8, grey) and there was a clear distinction on the ground between these squares of till and the occupation area spread.

The general area to the southwest of the structure is the most complicated and has resulted in potentially five more groupings. Phosphorus and aluminium are relatively enhanced in this area, next to pit/posthole [336]. The actual values of phosphorus range from $90-4750 \mathrm{ppm}$ across the whole sampled area. All of the values above $2000 \mathrm{ppm}$ (totalling seven sample readings) are within this area to the southwest of the central structure. These moderately enhanced levels of phosphorus do not suggest truly sustained intensive middening, animal processing or similar but might suggest a localised, potentially anthropogenic influence from general occupation or decomposing organic remains. It is possible that the entrance to the structure is at this southwest location and waste from the structure was deposited here, or that other activities such as food processing or the discard of bodily fluids occurred in this spot.

A total of 24 samples were taken from the western structure. These samples were generally found to be consistent in composition with the samples identified as till from the north of the central structure occupation area (Figure 21.5; grey squares). The exception to this was the southwestern-most sample square that consistently grouped with the central structure grouping when analysed within the complete dataset, and was similarly depleted of most elements relative to other samples from the western structure, except for phosphorus and calcium, which were near average so still not high. The probable reason for this pattern around the western structure is that the samples were taken from much further down the soil profile, in most cases about $0.1 \mathrm{~m}$ into the clayey sediment. Therefore, it is perhaps not surprising that these readings are similar to those taken as control samples in the till.

\section{Principal component analysis on the central occupation area}

Principal component analysis based on five elements ( $\mathrm{Al}, \mathrm{Ca}, \mathrm{Fe}, \mathrm{Mg}, \mathrm{Mn}$ ) also supported the interpretation that there was consistent depletion in the values from the central structure and occupation area relative to the

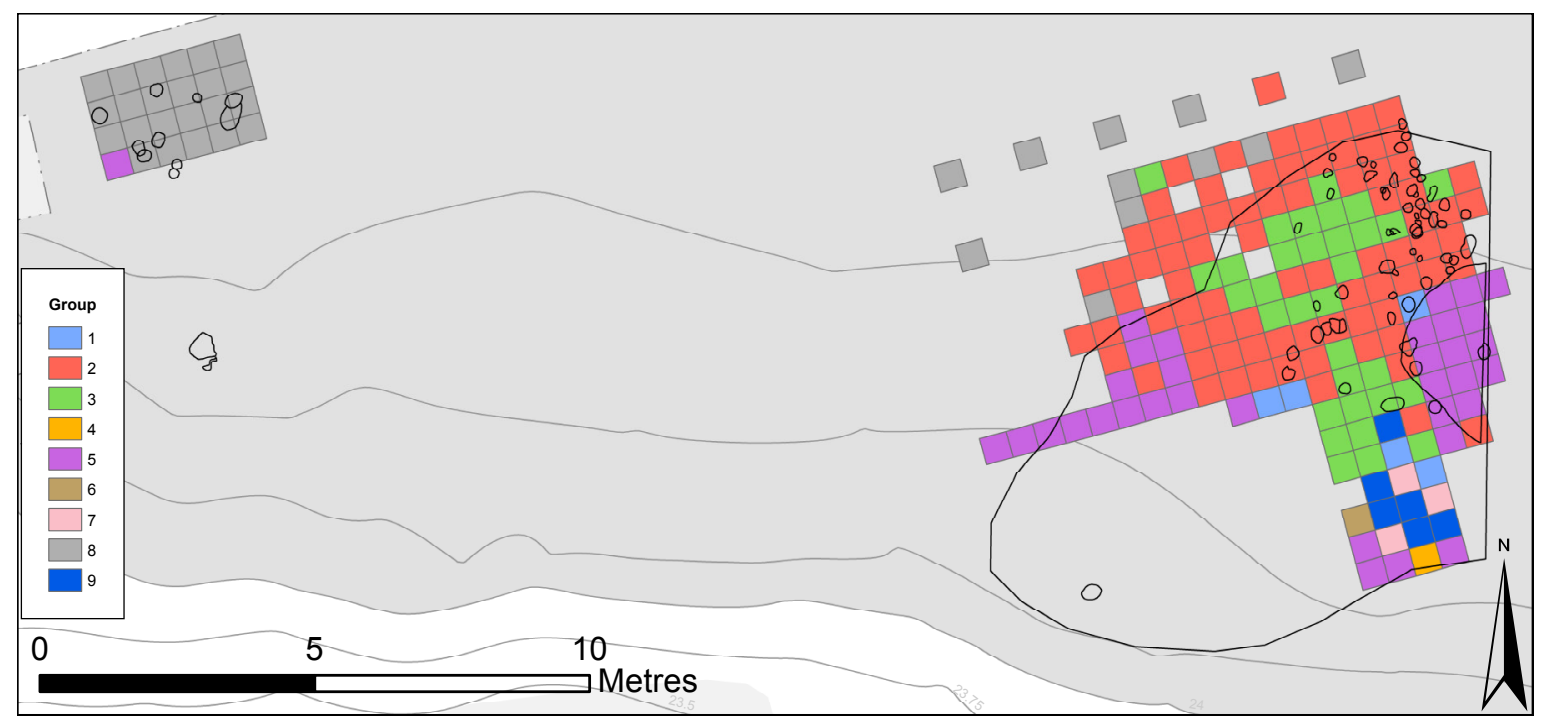

Figure 21.5: The western structure and central structure areas, with nine groupings specified for the complete dataset (Copyright Charlotte Rowley, CC BY-NC 4.0). 
till; the principal linear combinations of the variables separated out clear clusters from the structure samples and occupation spread contexts but these were compared to the more varied (less well clustered) till samples.

Principal component analysis revealed that the samples from the structure and occupation area formed localised groupings within statistical regions based on the readings of the five elements that could be incorporated into the model. The biplot (Figure 21.6) illustrates the relationships identified between the five variables (the vectors) and also the individually projected data (the scatter plot) in the space of the first two components (i.e. the most significant components).

Loading vectors that are close to one another indicate closely correlated variables. In addition, the closer to the axes, the more that element loads on the component represented by that axis. The loading vectors show that aluminium heavily loads on PC1, which is the most important component. Aluminium is in the same graph quadrant as magnesium and manganese. Magnesium and manganese are most strongly correlated to each other, but the other elements are less closely correlated to one another.

The projected scores show that those readings from the central structure (in red) group close together. They plot closest to the calcium vector, suggesting they are slightly more influenced by calcium than the other elements. However, the graph illustrates again how these samples are relatively depleted in all elements relative to most of the other samples (particularly manganese), considering their position on the left-hand side of the graph, opposite to the direction of the variable vectors. The structure readings do not overlap with the till sample scores (in black) at all, and only overlap or come close to some of the light and dark occupation spread (light and dark blue respectively) and southwest of structure (orange) sample scores.

The southwest of structure sample scores are most disperse in how they load onto these two components. They mainly overlap with till and dark occupation spread samples but they are generally dispersed quite differently, mostly being in the upper-right quadrant of the plot, i.e. with positive loading scores on both components. This suggests they are also quite different in nature, and this seems to relate to their iron and calcium content.

\section{Conclusions}

This study highlights the importance of careful sampling because the work is very time consuming and processing a large sample is relatively expensive. With hindsight, the samples from the western structure were sampled from too far down the soil profile. However, conducting geochemical analyses on the sediments from the central area has provided interesting data which correlates with archaeological features. The results show some interesting patterning in the area around the central structure and in particular the filled hollow of the central structure was clearly defined using the Grouping Analysis tool and the PCA. It had been assumed that an activity area, such as a structure, might have higher readings; however, this area appears to be relatively depleted in elements compared to other sampled areas, and this may be a result of keeping this area cleaner of waste products compared to other areas. This group 5 is also evident to the west of the central occupation spread: unfortunately this area was not fully sampled, but in the future it might be possible to assess more samples and test whether this group is well defined in that region, i.e. whether another structure may have existed in this area but was not visible as an archaeological feature.

The other area of particular interest is to the southwest of the structure, which may have been just outside the entrance to the central structure and which also featured an unusual pit/posthole filled with burnt flint and bone. This area appears to be more indicative of an occupied area featuring higher phosphorus/phosphate levels. Phosphorus/phosphate analysis is often favoured by archaeologists as it is often enhanced significantly by a wide variety of anthropogenic activities in relatively stable forms. However, analysing the phosphorus in isolation would not have facilitated the identification of the central structure at Star Carr. Middleton and Price $(1996,679)$ found that phosphorus was not a key element for the differentiation of interior spaces in their ethnoarchaeological study of a modern earthen floored house in a Mexican village either, probably due to the deliberate removal of organic debris from the structure. Phosphorus is probably the most reliable element for identifying a generally occupied area but, importantly, it is through the combined elemental readings, rather than studying individual elements in isolation, that groupings were identified at Star Carr. Therefore, perhaps the most important result of this work is that the method has potential: even though features are often lacking on Mesolithic sites, it may be possible to delimit 'invisible' structures in the future. 

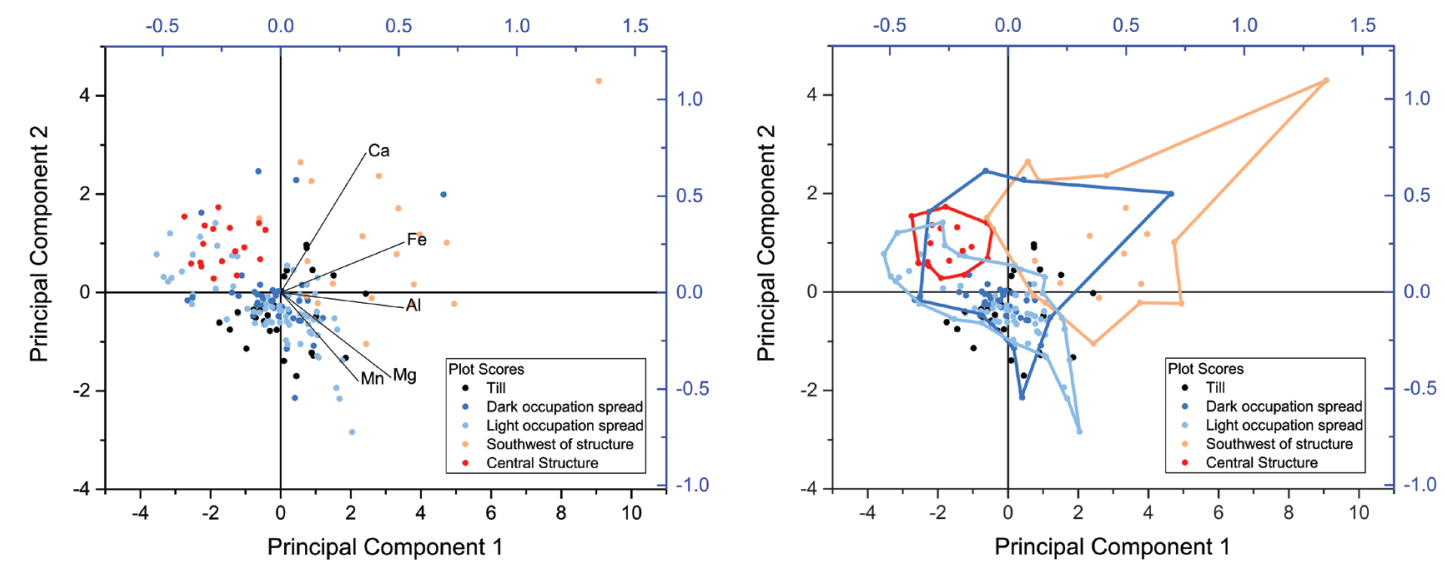

Figure 21.6: (left) a biplot illustrating the relationships between 1) the five elements (depicted as variable vectors) and their contribution to the components, 2) the individually projected data points for each sample and therefore 3) the relationship between the variable loadings on the components and the elements as shown by their proximity on the graph; data points are symbolised by area; (right) a plot of the same individually projected sample data points, highlighting the relationship of samples from different areas to the components (made by connecting the most dispersed points of each spread) (Copyright Charlotte Rowley, CC BY-NC 4.0). 
